\title{
Response to Response to Sharma Parpia et al. (2018): The accuracy of Canadian Nutrient File data for reporting phosphorus, potassium, sodium and protein in select meat, poultry and fish products
}

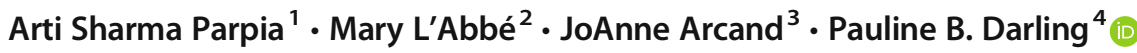 \\ Received: 3 May 2021 / Accepted: 11 May 2021 / Published online: 27 May 2021 \\ (C) The Canadian Public Health Association 2021
}

Dear Editor:

We read with great interest the response from Verreault et al. (2021). Our intention was to highlight for health care professionals in particular that there may be significant differences between the foods their patients are consuming and the values stated in the Canadian Nutrient File (CNF) (Sharma Parpia et al., 2018).

After making the adjustments to CNF comparison values suggested by Verreault et al. (2021), we continue to observe significant discrepancies in mean chemically analyzed and CNF values. We now report that $20 \%$ of the analyzed food categories have significant discrepancy for sodium (decreased from $30 \%$ ), $30 \%$ for potassium (decreased from $40 \%$ ), $20 \%$ for phosphorus (no change) and 30\% for protein (decreased from $40 \%$ ). As stated previously, our data are limited by geographic location.

Verreault et al. (2021) state that "management of patients with chronic kidney disease [CKD] should be based on the nutrient composition of the specific foods in their diets"; however, it is not practical to chemically analyze the specific foods of individual patients, nor do many such meats provide Nutrition Facts tables (NFt). The NFt, when available, may not include values for key nutrients of concern for CKD patients such as potassium and phosphorus (Health Canada, 2021). When Canadian health care providers require

Pauline B. Darling

pdarling@uottawa.ca

1 Diabetes Comprehensive Care Program, St. Michael's Hospital, Toronto, ON, Canada

2 Department of Nutritional Sciences, Faculty of Medicine, University of Toronto, Toronto, ON, Canada

3 Faculty of Health Sciences, Ontario Tech University, Oshawa, ON, Canada

4 School of Nutrition Sciences, Faculty of Health Sciences, University of Ottawa, Ottawa, ON K1H 8M5, Canada information about the nutritional composition of food, they may refer to the CNF. The CNF User Guide states that the $\mathrm{CNF}$ is suited for the assessment of diets and menu planning (Health Canada, 2015) by providing non-specific average values for foods. Proper interpretation of these data requires clear descriptions of food codes and presentation of standard deviations of the average values. Health Canada might further help guide CNF users in these areas.

We applaud staff at Health Canada who work on the CNF, and encourage increased food sampling across the country in order to improve the accuracy of CNF and its representativeness of the Canadian food supply.

\section{References}

Health Canada. (2015). Canadian Nutrient File - Users Guide. Compilation of Canadian Food Composition Data. https://www. canada.ca/en/health-canada/services/food-nutrition/healthy-eating/ nutrient-data/canadian-nutrientfile-compilation-canadian-foodcomposition-data-users-guide.html. Accessed 25 April 2021.

Health Canada. (2021). Food labelling changes. https://www.Canada.ca/ en/health-canada/services/food-labelling-changes.html. Accessed 26 April 2021.

Sharma Parpia, A., Darling, P. B., L’Abbé, M. R., Goldstein, M. B., Arcand, J., Cope, A., \& Shaikh, A.-S. (2018). The accuracy of Canadian Nutrient File data for reporting phosphorus, potassium, sodium and protein in selected meat, poultry, and fish products. Canadian Journal of Public Health, 109, 150-152.

Verreault, M.-F., Rondeau, I., Klutka, R., Cockell, K. A. (2021). Response to Sharma Parpia et al. (2018): The accuracy of Canadian Nutrient File data for reporting phosphorus, potassium, sodium and protein in selected meat, poultry, and fish products. Canadian Journal of Public Health, 112. https://doi.org/10.17269/ s41997-021-00538-z.

Publisher's note Springer Nature remains neutral with regard to jurisdictional claims in published maps and institutional affiliations. 